\title{
The Effects of Teppanyaki Restaurant Stimuli on Diners' Emotions and Loyalty
}

\begin{abstract}
This research examines the influence of restaurant stimuli on diners' emotions and loyalty to teppanyaki restaurants. In teppanyaki restaurants, chefs take orders from diners, prepare food in front of diners, and serve dishes to diners. Although the importance of chefs has been acknowledged by scholars, empirical research on the influence of chefs on diners has been scarce. To augment the literature on how chefs influence diners, this research incorporates "chef's image" into an extended Mehrabian-Russell model (M-R model) to conceptualize diner loyalty to teppanyaki restaurants. A total of 308 diners from Taiwan were recruited. After examining their completed questionnaires, this study found that chef's image, service quality, and food quality can affect the positive and negative emotions of diners. Moreover, other diners and restaurant atmospherics affect only the negative emotions of diners. Both positive and negative emotions can affect diner loyalty to teppanyaki restaurants.
\end{abstract}

Keywords: teppanyaki, chef's image, diners, emotions, loyalty 


\section{Introduction}

The restaurant industry has grown significantly since the 1980s. From the 1980s to 2011, global restaurant industry sales increased more than tenfold from US \$42.8 billion to $\$ 536.7$ billion (all monetary units are in US dollars) (Chen, Peng, \& Hung, 2015). Studies in restaurant consumption have burgeoned in recent years partially as a result of this development. Within the research of the restaurant industry, some scholars have been interested in dining behavior at upscale restaurants because these experiences can be an art form that gratifies multiple human senses and because food is an important medium in understanding a culture or society (Chang, Kivela, \& Mak, 2010; Lee \& Hwang, 2011; Min \& Lee, 2014). Although scholars have been examined some issues related to restaurant consumption behavior of diners, the role of chefs when promoting restaurants still requires further investigation (e.g., Chen et al., 2015; Jang \& Namkung, 2009; Lee \& Hwang, 2011; Peng \& Chen, 2015; Wu \& Liang, 2009).

For scholars who studied chefs' influence on restaurants, they suggested that chefs are crucial to restaurant performance (Kuroshima, 2010; Pratten; 2003a; 2003b; Zopiatis, 2010), especially in upscale restaurants (Byrne \& Whitehead, 2003; Halonen-Knight \& Hurmerinta, 2010; Harrington, Ottenbacher, \& Kendall, 2011; Johnson, Surelmont, Nicod, \& Revaz, 2005) and restaurants in which the chef must directly interact with diners, such as teppanyaki restaurants (Fang, Peng, \& Pan, 2013; Kuroshima, 2010; Lin \& Lin, 2006). For the aforementioned reasons, to remain competitive, restaurants must train their chefs and attract and retain chefs who are experienced, creative, and skillful (e.g., Batra, 2008; Chang et al., 2010; Law et al., 2008; Nam \& Lee, 2011). Studies on chef's influence on restaurants have been conducted; however, the focus has been placed on their influence on other staff, 
suppliers, and managers. Chef's influence on diners has been overlooked (e.g., Byrne \& Whitehead, 2003; Halonen-Knight \& Hurmerinta, 2010; Harrington et al., 2011; Johnson et al., 2005).

To augment the literature on how chefs influence diners, this research examines how teppanyaki restaurant stimuli (e.g., chefs, service staff, other diners, food quality, and atmospherics) can influence customers' emotions and loyalty using an extended Mehrabian-Russell model (M-R model). According to Fang et al. (2013), teppanyaki restaurants provide a unique on-the-spot dining experience as diners sit around an iron plate while the chef prepares the dishes as the customers place their orders. Diners can watch as the chef prepares food and demonstrates his/her cooking skills; moreover, they can interact with the chef and even have a conversation. In these restaurants, chefs become an ambassador for this type of dining culture. Such restaurants are popular in Japan, Taiwan, France, and the US (Fang et al., 2013; Kuroshima, 2010; Lin \& Lin, 2006).

Notably, teppanyaki restaurants are associated with Japanese culinary culture; however, Fang et al. (2013) and Lin and Lin (2006) noted that teppanyaki restaurants play a significant role in Taiwan's hospitality and tourism industries and appeal to both local diners and visitors from abroad. Although teppanyaki-style restaurant represents a major type of catering business in Taiwan, its market size can be difficult to measure (Fang et al., 2013). By considering information from Taiwan’s Commerce Industrial Service Portal (2016) and Tripadvisor (2016), there are approximately 370 registered teppanyaki restaurants in Taiwan, but there are nearly 2,000 restaurants have teppanyaki dishes as part of their menu. Some restaurants that offer teppanyaki dishes are not registered as teppanyaki restaurant because only some of the dishes are prepared in front of diners. 
Investigating how teppanyaki chefs affect diners not only contributes to the literature on hospitality management and service marketing but it also has practical implications. Previous studies of restaurant service quality and performance have primarily focused on the service quality of service staff, such as waiters and waitresses (e.g., Jang \& Namkung, 2009; Mohsin \& Lockyer, 2010). In teppanyaki restaurants, chefs share some of the responsibilities of service staff by taking orders from diners and serving dishes to diners. Nevertheless, chefs differ from frontline service staff not only in their role but also in their food-related experience, creativity, and knowledge. The findings of this study can help teppanyaki restaurants and other restaurants in which chefs must directly serve diners to increase customer loyalty by assessing their chefs and service staff's roles and responsibilities.

This research has four objectives. First, this research explores how diners' emotions are influenced by chef's image. For this purpose, a "chef's image” factor is included in the modified M-R model. Second, this study tests the influence of other customers in the teppanyaki restaurant context by investigating the effect of an “interaction with other customers" variable. Third, the influences of teppanyaki restaurants' service quality, food quality, and atmospherics are examined; furthermore, positive emotions’ and negative emotions’ mediating effects will be explored. By exploring positive emotions' and negative emotions' mediating effects, this present study might further contribute to the literature on consumer emotions. Finally, this study advances a number of managerial implications for tourism and hospitality practitioners to consider.

\section{Literature Review}

\subsection{Mehrabian-Russell model}


To further understand the influence of chefs on diners' emotions and behavior, this research aims to examine customers' emotions and loyalty through an extended M-R model. Mehrabian and Russell's (1974) study examines the influences of environmental stimuli on the emotions and responses of individuals. According to Mehrabian and Russell, stimuli can affect the emotions of individuals, which can in turn influence their responses. Scholars have used the M-R model and its modifications to examine consumers’ shopping behavior (Kaltcheva \& Weitz, 2006; Ong \& Khong, 2011; Tai \& Fung, 1997; Yuksel, 2007), and web surfers’ online shopping behavior (Koo \& Ju, 2010). The M-R model is suitable for examining how teppanyaki restaurants stimuli influence diners’ emotions because these restaurants use their environment to promote diners' positive emotions and subsequent behaviors, such as repeat visits and recommendations (e.g., Chen et al., 2015; Jang \& Namkung, 2009; Liu \& Jang, 2009).

Among the studies on diners' behavior, the work conducted by Chen et al., (2015), Jang and Namkung (2009), and Liu and Jang (2009) is most relevant to the current research. Liu and Jang (2009) investigate the relationships among dining atmospherics, emotional responses, perceived value, and behavioral intention in the context of restaurants. They find that atmospherics influence diners' positive and negative emotions, which, in turn, affect their behavioral intentions. Liu and Jang's (2009) study is one of the first hospitality studies to include both positive and negative emotions in a modified M-R framework. Furthermore, it is one of the few studies to confirm that both positive and negative emotions affect individuals' behavioral intentions.

Because it uses an extended M-R model to examine the impact of luxury restaurant-specific stimuli (i.e., product quality, atmospherics, and service quality) on 
diners’ emotions, Jang and Namkung's (2009) study has direct implications for the present study's framework. Their results show that service quality and atmospherics positively affect diners' positive emotions, whereas product quality is negatively correlated with diners’ negative emotions. Moreover, their results show that only positive emotions can affect diners’ subsequent behavioral intention. Furthermore, Jang and Namkung (2009) confirm that service quality and atmospherics can directly influence behavioral intentions, while product quality does not exert such an effect.

Chen et al. (2015) examine Taiwanese diners’ luxury restaurant consumption behavior by incorporating customers' interactions with other customers into an extended M-R model. Their results show that luxury restaurants' stimuli can affect diners' emotions, which, in turn, can affect their loyalty. To be specific, restaurants' service quality and atmospherics are found to have a significant impact on diners' positive emotions, while food quality, service quality, and interactions with other customers can affect diners' negative emotions. Additionally, both positive and negative emotions can influence diners' loyalty. Interestingly, food and beverages, which are arguably a restaurant's core products, have no influence on diners' positive emotions.

Although scholars have applied the M-R model to restaurant-consumption context, areas for future research exist. First, the factors that affect diners' positive emotions and negative emotions can be further investigated. For instance, service quality had no impact on negative emotions in Jang and Namkung’s (2009) study; however, it can affect diners' negative emotions significantly in Chen et al.'s (2015) research. Moreover, the influence of "interaction with other customers" can be further explored because it was a relatively new addition to the M-R model when applied to restaurant consumption scenarios. 
Second, when investigating consumption experiences, Westbrook (1987) found that positive and negative affect can both influence consumers' satisfaction and their behavior. In other words, the joint occurrence of positive emotions and negative emotions, such as pleasant and unpleasant states, needs to be considered when examining consumer behavior. In the context of hospitality management research, Han and Back (2008) proposed and confirmed that positive emotions and negative emotions have a separate role in forming consumer loyalty when examined separately. In addition, given upscale restaurants often use multiple methods to gratify diners' senses (Chang et al., 2010; Lee \& Hwang, 2011; Min \& Lee, 2014), their effects on diners' emotions can be complex. For the purpose of obtaining a better understanding of restaurant-specific stimuli's influences on diners and scholars have suggested, this present research adapts the unipolar approach to examine emotions (i.e., the coexistence of positive and negative emotions).

By including positive emotions and negative emotions as two variables, this present study can contribute to the environmental psychology literature and hospitality management research because consumers are more interested in fine dining than they have been in the past (Wu \& Liang, 2009), but the results regarding negative emotions’ influence have been inconsistent. For example, Liu and Jang (2009) and Chen et al. (2015) confirmed that both types of emotions can affect diners, whereas Jang and Namkung (2009) found that only positive emotions can affect diners.

Third, positive emotions’ and negative emotions’ ability to mediate stimuli’s effects on diners' loyalty warrant further exploration because previous findings have been inconsistent. Jang and Namkung's (2009) results indicated that negative emotions had insignificant impact on loyalty; therefore, it cannot mediate between 
restaurant stimuli and diners' loyalty; however, Chen et al.'s (2015) findings on luxury restaurant consumption behavior showed negative emotions fully mediated the relationships between service quality and loyalty and interaction with other customers and loyalty. These two studies also disagreed on positive emotions' mediating effect. Jang and Namkung found it partially mediated the relationships between atmospherics and loyalty and service quality and loyalty. Chen et al. confirmed positive emotions fully mediated these two relationships. Further examination of emotions' mediating effects has implications to the hospitality management literature because it might be able to add new evidence to the discussion of whether diners' emotions are relevant in upscale restaurant consumption-related studies.

\subsection{Literature on restaurant chefs and other customers}

Academic studies of chefs have confirmed that chefs play an important role in restaurants (Byrne \& Whitehead, 2003; Halonen-Knight \& Hurmerinta, 2010; Harrington et al., 2011; Johnson et al., 2005). Based on an examination of 92 chefs (e.g., junior sous chefs, sous chefs, chefs, and executive chefs) working in Cyprus's independent restaurants and hotel establishments, Zopiatis (2010) suggested that a good chef must excel in the following categories: leadership, interpersonal skills, conceptual-creative ability, administrative ability, and technical skills. Studying chefs in sushi bars and teppanyaki restaurants, Fang et al. (2013), Kuroshima (2010), and Lin and Lin (2006) argued that good chefs require excellent interpersonal skills, technical skills, and creativity. Because of the importance of chefs and the number of skills that good chefs must master, the recruitment, training, and retention of good chefs are among the major challenge confronted by restaurant managers and owners (Pratten, 2003a; 2003b). Although the importance of chefs has been acknowledged by scholars, empirical research on the influence of chefs on diners has been limited. For 
example, Lin and Lin (2006) developed the “chef's image” scale to measure the influence of teppanyaki chefs have on diners; however, this variable’s relationships with existing theories and frameworks have not been explored.

In the marketing and tourism literature, researchers (e.g., Baker \& Cameron, 1996; Brocato, Voorhees, \& Baker, 2012; Chang \& Horng, 2010, Choo \& Petrick, 2014) have recognized that shoppers and tourists can affect one another's experiences and emotions. In contrast to private dining, restaurants such as teppanyaki restaurants serve multiple diners simultaneously. Furthermore, diners at teppanyaki restaurants sit next to one another in front of the chef (Fang et al., 2013). Therefore, these customers are likely able to influence one another through their behavior and manner (Fang et al., 2013; Wu \& Liang, 2009). Nonetheless, only a few scholars have examined the influence of other diners in a restaurant setting (e.g., Chen et al., 2015; Wu \& Liang, 2009). The results on other diners' influence have been inconsistent. Wu and Liang's (2009) research on luxury restaurant consumption experience showed other diners can affect customers' perceived experiential value of luxury restaurants positively. Chen et al.'s (2015) study on luxury restaurant consumption behavior found other diners can affect diners' negative emotions, but not their positive emotions. Additional research on the effect of this factor can further contribute to the hospitality management literature.

\section{Research framework and hypotheses}

Based on a review of studies related to the M-R model and chef influences, this paper adopts the models used by Chen et al. (2015). Their framework shows that restaurant-specific stimuli (i.e., atmospherics, food quality, service quality, and other customers) can affect the positive and negative emotions of diners; moreover, both types of emotions affect diners' loyalty. When examining restaurant-specific stimuli's 
effects, positive emotions’ and negative emotions’ mediating effects will also be explored. In addition, the current study incorporates “chef's image” into the proposed model to investigate the influence of chefs on diners. The following section provides details regarding this study's proposed framework and hypotheses (Figure 1).

*Please insert Figure 1 about here.

First, this study hypothesizes that interaction with other customers can influence diners' emotions. In the consumer behavior literature, emotions are defined as affective responses that are specifically generated during product use or consumption experiences (Han \& Ryu, 2009; King \& Meiselman, 2010; King, Heiselman, \& Carr, 2010). The influences of other consumers have been documented in retail settings and luxury goods consumption scenarios (Baker \& Cameron, 1996; Brocato et al., 2012; Berthon, Pitt, Parent, \& Berthon, 2009). According to Wu and Liang, scholars who study restaurants must consider the appearance and behavior of other customers and their interactions with service staff and other customers.

At teppanyaki restaurants, each chef serves multiple diners, and the diners sit next to one another in front of the chef; therefore, good interactions with other diners can be expected to influence customers' emotions. Customers can be expected to experience positive emotions regarding the restaurant if other customers are polite and well behaved. By contrast, diners are likely to experience negative emotions if they perceive other customers as rude and ill mannered. In restaurant consumption research, Wu and Liang (2009) confirmed that diners' experiences are positively influenced by other diners. Chen et al.’s (2015) study hypothesized and confirmed that “interaction with other customers” is a factor that can contribute to negative emotions in luxury restaurant customers but not to their positive emotions. Research on this factor is relatively scarce and inconsistent. Further investigation can provide further 
evidence on how diners are affected by other customers. Based on the preceding discussion, this research examines the following hypotheses:

H1a: Diners’ perceptions of a teppanyaki restaurant's other customers have a positive effect on positive emotions.

H1b: Diners’ perceptions of a teppanyaki restaurant's other customers have a negative effect on negative emotions.

The second hypothesis that will be examined concerns how a chef's image influences diners' emotions. "Chef's image” refers to customers' overall perceptions of a chef's interpersonal skills, technical skills, and creativity (Fang et al., 2013; Kuroshima, 2010; Lin \& Lin, 2006; Zopiatis, 2010). In the teppanyaki restaurant context, chefs with good interpersonal skills, communication skills, creativity, and technical skills are important because chefs take orders from diners, prepare food in front of diners, and serve dishes to diners. In addition, chefs engage in conversation with diners to understand their preferences (Fang et al., 2013; Lin \& Lin, 2006). If diners perceive their chef as having a positive image (e.g., being creative and proficient in making delicious dishes) they are more likely to feel positive emotions about the restaurant. Conversely, if the chef image is perceived as poor (e.g., not being knowledgeable about ingredients and having poor interpersonal skills), then diners’ negative emotions about the restaurants will increase. Some circumstantial findings support the significance of this factor (e.g., Fang et al., 2013; Ko \& Hsiao, 2008; Kuroshima, 2010; Lin \& Lin, 2006; Zopiatis, 2010), but no known study has empirically examined the impact of chef's image on diners' emotions. This study thus proposes the following hypotheses:

H2a: Diners' perceptions of the chef's image have a positive effect on positive 
emotions.

H2b: Diners' perceptions of the chef's image have a negative effect on negative emotions.

The third hypothesis examines the influence of service staff on diners' emotions. To examine the interaction between service staff and diners, this study focuses on service quality, which refers to customers' overall perceptions of the relative inferiority or superiority of a service provider (Parasuraman, Zeithaml, \& Berry, 1988). In teppanyaki restaurants, service staff escort customers to their seats, serve beverages, and assist customers when needed. Although some of their responsibilities overlap with those of chefs, service staff represent an important part of teppanyaki restaurants (Fang et al., 2013; Kuroshima, 2010). The literature has confirmed that the staff's service quality affects diners' emotions (e.g., Jang \& Namkung, 2009; Wu \& Liang, 2009). If staff members are helpful, knowledgeable about the menu, and reliable, then diners will have positive emotions about the restaurant. Conversely, diners will feel negative emotions if the staff are unreliable and unprofessional. Although service quality in restaurant settings has been examined, this factor is worthy of further investigation because some service staff duties in teppanyaki restaurants are handled by chefs. This study thus proposes that customers' perceptions of staff service quality strengthen both their positive and negative emotions when dining in teppanyaki restaurants.

H3a: Diners’ perceptions of a teppanyaki restaurant’s service quality have a positive effect on positive emotions.

H3b: Diners’ perceptions of a teppanyaki restaurant’s service quality have a negative effect on negative emotions. 
Fourth, in studies of retail shops, convention centers, and shopping malls, Kaltcheva and Weitz (2006), Koo and Ju (2010), and Ong et al. (2012) found that atmospherics have a significant impact on customers and visitors. Kotler (1973) defined atmospherics as the conscious design of space to create certain buyer effects. In the restaurant context, Liu and Jang (2009) found that atmospherics affect the positive and negative emotions of diners. Moreover, Jang and Namkung (2009) indicated that positive atmospherics can contribute to luxury restaurant diners’ positive emotions. In teppanyaki restaurants, where food is prepared and served in front of diners, managers and owners must take additional precautions in designing the physical space and atmosphere. Suitable lighting, temperature, music, and décor can contribute to diners' positive emotions about a restaurant. However, poor atmospherics are likely to cause diners to experience negative emotions. Hence, this study hypothesizes that atmospherics affect the positive and negative emotions of diners at teppanyaki restaurants:

H4a: Diners’ perceptions of a teppanyaki restaurant's atmospherics have a positive effect on positive emotions.

H4b: Diners’ perceptions of a teppanyaki restaurant's atmospherics have a negative effect on negative emotions.

The fifth hypothesis examined in this research posits the influence of food quality on diners' emotions. According to Kwun and Oh (2006), product quality in the restaurant context refers to the quality of food and beverages. In their studies on restaurant consumption behavior, Jang and Namkung (2009) and Chen et al. (2015) noted that the presentation, tastiness, and freshness of food are important aspects of food quality in upscale restaurants. Furthermore, the nutritional value of ingredients should also be considered. In a teppanyaki restaurant, food is often prepared in front 
of diners from the raw to finished states (Lin \& Lin, 2006). Therefore, better food quality should be positively correlated with the positive emotions of diners, whereas inferior food quality should cause diners to feel negative emotions about the restaurant. Jang and Namkung (2009) and Chen et al. (2015) confirmed that the freshness and tastiness of food can significantly affect the positive and negative emotions of consumers. Based on existing findings in the literature, the current study hypothesizes that a teppanyaki restaurant's food quality can strengthen both the positive and negative emotions of diners:

H5a: Diners' perceptions of a teppanyaki restaurant's food quality have a positive effect on positive emotions.

H5b: Diners’ perceptions of a teppanyaki restaurant's food quality have a negative effect on negative emotions.

This study examines how positive and negative emotion affects diners' loyalty. In the context of this study, loyalty refers to a diner's intention to consistently revisit the same luxury restaurant. Oliver (1999) defined loyalty as a deeply held commitment to repurchase or repatronize a preferred product or service consistently in the future. In studying restaurant customers, Jang and Namkung (2009) observed that positive emotions or satisfaction with a product can result in higher levels of loyalty. In their research on Asian diners, Liu and Jang (2009) and Chen et al. (2015) showed that negative emotions can reduce customer loyalty. In this study’s context, customers who are pleased, excited, and comfortable with a teppanyaki restaurant are expected to be more likely to become repeat customers and to recommend the restaurant to others, whereas customers who feel irritated, disappointed, and disgusted toward a teppanyaki restaurant are less likely to recommend or revisit it in the future. As previously noted, few scholars have examined the influence of negative emotions. 
Additional research on the effects of this factor may thus contribute to the hospitality management literature. Based on the preceding discussion, the current study examines the following hypotheses in the context of teppanyaki restaurants:

H6a: Diners’ positive emotions have a positive effect on their loyalty to teppanyaki restaurants.

H6b: Diners' negative emotions have a negative effect on their loyalty to teppanyaki restaurants.

Finally, the current research proposes that positive and negative emotions can mediate the relationship between stimuli and responses. According to Mehrabian and Russell (1974), stimuli can affect individuals' emotions, which can, in turn, influence $\underline{\text { their responses. In previous restaurant research that adapted the M-R model, Chen et }}$ al. (2015) and Jang and Namkung (2009) test and partially support the notion that emotions have the ability to mediate the relationship between restaurant stimuli and diners' loyalty or behavioral intentions. However, additional research might further clarify the mediating role of positive and negative emotions. For instance, Chen et al. (2015) examine the relationship between other customers and diners' loyalty; nonetheless, "interaction with other customers" is not included in Jang and Namkung's (2009) study. Additionally, negative emotions have no mediating effect in $\underline{\text { Jang and Namkung's research, while they fully mediate the relationships between }}$ service quality and loyalty and between interaction with other customers and loyalty. $\underline{\text { To further explore positive and negative emotions’ ability to mediate restaurant }}$ stimuli and diners' loyalty, the present study examines the following hypotheses:

H7a: Diners' positive emotions mediate the influence of restaurant stimuli (i.e., chef's image, atmospherics, food quality, service quality, and other 
customers) on diners' loyalty.

H7b: Diners' negative emotions mediate the influence of restaurant stimuli (i.e., chef's image, atmospherics, food quality, service quality, and other customers) on diners’ loyalty.

\section{Method}

\subsection{Sampling and data collection methods for the quantitative studies}

To examine the proposed framework, this research focused on Taiwan's luxury hotels that served teppanyaki dishes. By luxury hotels, this study referred to four- and five-star hotels (Wu \& Liang, 2009). According to Wu and Liang (2008), four- and five-star hotel restaurants are subject to stringent inspections; therefore, the quality of the restaurants considered in this study can be expected to be rather consistent. The sampled hotel restaurants were divided into the following geographic locations: Taipei City, Taichung City, and Kaohsiung City. These cities are Taiwan’s three largest cities with 27, 13, and 12 four-star and five-star hotels, respectively (Taiwan Stay, 2016).

Questionnaires were distributed and collected by research students. Using an interception technique, trained interviewers selected individuals who had finished dining and were leaving the restaurants. Based on King et al.'s (2010) recommendation, the most appropriate time to evaluate emotions is during or immediately after exposure to a stimulus. The interviewers were instructed to rotate between hotels on daily basis. Customers were asked to participate in the survey on a voluntary basis. A purposive sampling technique was used to collect data. To qualify for the interview, potential participants had to 1) be over the age of 18 and 2) have previously dined at a teppanyaki restaurant for leisure purposes. When preparing and conducting this research, the authors followed the research ethics guideline prepared 
by our universities’ research ethics committees.

After eight weeks' of data collection, 473 individuals were asked to complete the questionnaire and a total of 308 questionnaires were deemed effective, resulting in a valid return rate of $65.1 \%$. The number of survey collected and the number of usable survey of this current study were in line with other restaurant research that used onsite data collection method (Jang \& Namkung, 2009; Liu \& Jang, 2009; Chen et al., 2015; Ryu et al., 2012). The participants of this research visited 12 restaurants. According to these restaurants' managers, the average price for dinner is approximately \$69 per person, ranging between \$25 and \$206 (excluding service charges and tips). This pricing is consistent with Chen et al.'s (2015) definition of luxury restaurants in the Taiwanese context. The demographic breakdowns of the sample set can be found in Table 1.

* Please insert Table 1 here

\subsection{Questionnaire design}

The participants completed a 27-question survey that included four items for food quality (Jang \& Namkung, 2009), three items for service quality (Chen et al., 2015), three items for interaction with other customers (Chen et al., 2015), three items for atmospherics (Liu \& Jang, 2009; Jang \& Namkung, 2009), nine items for chef’s image (Lin \& Lin, 2006), three items for diners’ positive emotions (Liu \& Jang, 2009; Jang \& Namkung, 2009), three items for diners’ negative emotions (Liu \& Jang, 2009; Jang \& Namkung, 2009), and three items for loyalty (Liu \& Jang, 2009; Ryu et al., 2010). A seven-point Likert-type scale was used when designing the items. Because Jang and Namkung (2009), Lin and Lin 2006), Liu and Jang (2009), and Ryu et al. (2010) used seven-point Likert-type scale to study diners' behavior in restaurants, it 
was not necessary for this current study to modify the questions used in their studies. The target research question under examination was "How will teppanyaki restaurant stimuli influence diners' emotions and loyalty?” All of the variables in the model (Figure 1) were measured using multiple items and were found to be reliable, with Cronbach’s alphas ranging from 0.74 to 0.94 . The items for each variable are presented in Table 2.

* Please insert Table 2 here

\section{Data Analysis}

\subsection{Factor analysis}

The data were analyzed using IBM SPSS AMOS 20. The whole sample (n=308) was randomly split into two halves, one as a calibration sample $(\mathrm{n}=148)$ and the other as a validation sample ( $\mathrm{n}=160$ ) (Huang \& Hsu, 2010). EFA was first used to identify the underlying structure of a study's construct. Then, CFA was used to test whether the structure could form an acceptable measurement model for the construct, with adjustments when necessary.

An EFA was conducted on this study's sample ( $\mathrm{N}=148)$ using the principal component method with varimax rotation to determine the dimensions of the scale (Anderson \& Gerbing, 1988). After a series of EFA to purify measurement indictors, the factor structure of this research's model is deemed reliable using Bartlett's $\chi 2$ test, the KMO test and Cronbach’s alpha (Lehto, O’Leary, \& Morrison, 2004). ‘[The chef] makes delicious dishes' was removed due to cross loading. After EFA, five factors were extracted from items within stimuli, two factors from emotions, and one single factor from loyalty. The Cronbach’s alpha of all constructs was above 0.70, indicating satisfactory reliability for the overall scale and all of the extracted factors (Table 2). 


\subsection{Measurement model}

Based on the results of a CFA $(\mathrm{N}=160)$, this research analyzed the convergent validity, discriminant validity, and composite reliability of all multi-item scales following guidelines from the literature (Fornell \& Larcker, 1981). Additionally, CFA was performed for each construct to ensure that the results were satisfactory. The results are presented in Table 3. First, the composite reliability of the research constructs, which indicates the internal consistency of multiple indicators for each construct, ranged from 0.80 to 0.94 . This result exceeds the recommended threshold outlined by Bagozzi and Yi (1988). Second, convergent validity was assessed in terms of factor loadings and average variance extracted (AVE). According to Fornell and Larcker (1981), AVE is the average variance shared between a construct and its measurement. As shown in Table 3, the factor loadings for all items were higher than 0.70 , and the AVE values ranged from 0.58 to 0.83 ; hence, convergent validity was confirmed (Fornell \& Larcker, 1981).

Third, discriminant validity was assessed by comparing the AVE of each individual construct with the shared variances between this individual construct and all other constructs. Because the AVE value for each construct was greater than the squared correlation between constructs, discriminant validity was assured (Table 4). After CFA was performed based on Bagozzi’s (1983) and Kline’s (2005) recommendations, this study's variables, composite reliability, convergent validity, and discriminant validity were deemed acceptable, thus indicating that the items were suitable for using the average of each factor. It should also be mentioned that the CFA results obtained from analyzing each construct were satisfactory.

*Please insert Table 3 here 
*Please insert Table 4 here

\subsection{Measurement model fit}

The results obtained using structural equation modeling reveal a good fit $\left(\chi^{2}=589.87, d f=277, \chi^{2} / d f=2.129 ; p<0.001, \mathrm{RMSEA}=0.061, \mathrm{CFI}=0.954, \mathrm{NFI}=0.917\right.$, TLI=0.946). In other words, the results of this study provide support for the proposed framework. Regarding the hypotheses, H1a is rejected, but H1b is supported with structural estimates of $-0.03(\mathrm{t}=-0.49, p>0.1)$ and $-0.23(\mathrm{t}=-2.80, p<0.01)$, respectively. This outcome indicates that a teppanyaki restaurant's other customers significantly affect the negative emotions of diners but not their positive emotions. H2a and H2b are supported with structural estimates of $0.20(\mathrm{t}=3.06, p<0.01)$ and $-0.35(\mathrm{t}=-4.63$, $p<0.001)$, respectively. That is, a teppanyaki restaurant's chef affects the positive and negative emotions of diners. This study's findings also support H3a and H3b. The structural estimates are $0.37(\mathrm{t}=4.92, p<0.001)$ and $-0.60(\mathrm{t}=-7.02, p<0.001)$, respectively. This outcome indicates that a teppanyaki restaurant's service quality has a significant effect on diners' positive and negative emotions. Although the findings do not support H4a, they do support H4b. The structural estimates are -0.04 ( $\mathrm{t}=-0.45$ $p>0.1)$ and $-0.27(\mathrm{t}=-2.68, p<0.01)$, respectively. A teppanyaki restaurant's atmospherics cannot affect diners’ positive emotions, but they can influence diner negative emotions. Furthermore, the results of the analysis support H5a and H5b with structural estimates of $0.17(\mathrm{t}=2.32, p<0.01)$ and $-0.17(\mathrm{t}=-2.12, p<0.01)$, respectively. Food quality influences the positive and negative emotions of diners. Finally, the results of this study support H6a but not H6b. The structural estimates are 0.43 $(\mathrm{t}=7.17, p<0.001)$ and $-0.25(\mathrm{t}=-5.35, p<0.001)$, respectively, indicating that both positive and negative emotions affect diners' loyalty to a teppanyaki restaurant (Table 5 and Figure 2). 
*Please insert Table 5 here

*Please insert Figure 2 here

The corrected $\mathrm{R}^{2}$ in Figure 2 refers to predictor variables' explanatory power on $\underline{\text { the respective construct (Ali, Rezaei, Hussain, \& Ragavan, 2014). Positive emotions }}$ explain $44 \%$ of diners' loyalty, whereas negative emotions explain $57 \%$ of diners' loyalty. According to Chin, Peterson, and Brown’s (2008) classification, positive and $\underline{\text { negative emotions’ influences on loyalty are both moderate. }}$

\subsection{Positive Emotions and negative emotions' mediating effect (H7a and H7b)}

Preacher and Hayes’s (2008) guidelines were used to examine the mediating effect of positive emotions. First, it was found that chef's image, service quality, and food quality were directly associated with loyalty. It was also found that chef's image, service quality, and food quality were positively related to positive emotions. Finally, $\underline{\text { the results indicated that the mediator, positive emotions, was positively associated }}$ $\underline{\text { with loyalty. }}$

Because the a-paths and b-paths were significant, the mediation analyses were tested using the bootstrapping method with bias-corrected confidence estimates (MacKinnon, Lockwood, \& Williams, 2004). In the present study, a 95\% confidence interval of the indirect effects was obtained with 5,000 bootstrap resamples (Preacher $\underline{\text { \& Hayes, 2008). The results of the mediation analysis confirmed the mediating role of }}$ positive emotions in the relationships between the environmental stimuli variables (i.e., chef's image, service quality, and food quality) and loyalty. Moreover, the results indicated that the direct effect of service quality on loyalty changed to non-significant when controlling for positive emotions, which suggested full mediation. The direct effects of chef's image on loyalty and of food quality on loyalty remained significant when controlling for positive emotions, which suggested partial mediation. Based on 
the results presented above, H7a is partially supported.

The same procedure was used to examine the mediating effect of negative emotions. First, it was found that interaction with other customers, chef's image, service quality, atmospherics, and food quality were directly associated with loyalty. It was also found that interaction with other customers, chef's image, service quality, atmospherics, and food quality were positively related to negative emotions. Finally, the results indicated that the mediator, negative emotions, was positively associated with loyalty.

The results of the mediation analysis confirmed the mediating role of negative emotions in the relationships between the environmental stimuli variables (i.e., interaction with other customers, chef's image, service quality, atmospherics, and food quality) and loyalty. Moreover, the results indicated that the direct effects of service quality on loyalty and of interaction with other customers on loyalty became non-significant when controlling for negative emotions, which suggested full mediation. The direct effects of chef's image on loyalty, of food quality on loyalty, and of atmospherics on loyalty remained significant when controlling for negative emotions, which suggested partial mediation. Based on the results presented above, H7b is supported. Table 6 summarizes the statistics regarding the indirect and direct relationships essential for the examination of mediating effects.

*Table 6 about here

\section{Discussion and Implications}

As previously discussed, although chefs significantly contribute to restaurant success and failure, recent tourism and hospitality studies offer little information on the influence of restaurant chefs (Byrne \& Whitehead, 2003; Halonen-Knight \& Hurmerinta, 2010; Harrington et al., 2011; Johnson et al., 2005). Because of this gap 
in the literature, restaurants that require chefs to serve diners, such as teppanyaki restaurants and sushi bars, do not fully understand how to effectively satisfy the needs of their customers. Therefore, to augment the literature, this study examines the influence of chefs on diners' emotions and loyalty through a modified M-R model. Considering the results of the data analysis, several issues are worthy of further discussion.

\subsection{Theoretical implications: the influence of emotions}

Studies employing the M-R model have consistently indicated that positive emotions can positively affect loyalty; however, the literature contains fewer discussions of the influence of negative emotions. Furthermore, the findings concerning this relationship have been inconsistent. For instance, the findings of Liu and Jang (2009) and Chen et al. (2015) supported this relationship, whereas the work of Jang and Namkung (2009) did not.

This study is consistent with the finding of Liu and Jang (2009) and Chen et al. (2015) that negative emotions significantly influence the loyalty of teppanyaki restaurant diners. This result has two possible explanations: (1) fine dining is a leisure activity that is valued by middle-class consumers and their families (Lee \& Hwang, 2011; Wu \& Liang, 2009) and (2) the competition between teppanyaki restaurants in Taiwan is intense (Fang et al., 2013). In Taipei, Taichung, and Kaohsiung, multiple four- and five-star hotels have teppanyaki restaurants. Additional teppanyaki restaurants can also be found on the major shopping avenues. Diners can choose to patronize other teppanyaki restaurants with relative ease. For these two reasons, diners are unlikely to revisit, repurchase or recommend a restaurant if they experience negative emotions after their visit. 
In the investigation of both positive and negative emotions in this study's framework, the findings confirm that both types of emotions are significant in determining customers' loyalty to teppanyaki restaurants. By following the unipolar approach to emotions (i.e., positive and negative emotions coexist) in Han and Back (2008), Jang and Namkung (2009), Liu and Jang (2009), and Chen et al. (2015) rather than the traditional M-R model's bipolar approach (i.e., either positive or negative emotions), this study demonstrates that both positive and negative emotions influence loyalty and that teppanyaki restaurant stimuli affect diners' positive and negative emotions in different ways. Furthermore, the correlation between these two variables is less than 0.5. Therefore, positive and negative emotions are different constructs. This result provides additional insight for the environmental psychology literature on positive and negative emotions.

\subsection{Theoretical implications: the effects of stimuli and the mediating effects of} emotions

Because this study examines positive and negative emotions separately, the effects of stimuli can provide more detailed insight into the factors that affect diners. Moreover, to contribute to the hospitality management literature and the M-R model, this present study also examined these two emotions' mediating effect. Five topics related to teppanyaki restaurant stimuli merit further discussion.

First, teppanyaki restaurants provide a unique on-the-spot dining experience and are popular in Japan, Taiwan, France, and the US. To take chef's influences on diners into account, Lin and Lin (2006) developed the scale to measure “chef's image”. However, this variable's relationships with existing theories and frameworks have been limited. One the main contributions of this research is the incorporation of “chef's image” into an extended M-R model. In restaurants in which chefs directly 
serve diners, chefs have several opportunities to present themselves to diners; therefore, chefs can evoke positive emotions in diners (e.g., excitement, joyfulness, and peacefulness) using their interpersonal skills, creativity, and technical skills. If chefs have poor skills or lack an aesthetic sense, diners are likely to be disappointed, displeased, or even angry.

Additionally, the current study also examined positive emotions and negative emotions' ability to mediate between chef's image and diners' loyalty. Chefs with good image can affect diners' loyalty directly and through affect their emotions' first. It demonstrates the importance of a good chef in high-end teppanyaki restaurant's context. Additionally, this study’s finding shows that chefs with poor image cannot affect diners' loyalty directly. In other words, chef image’s negative influence on diners’ loyalty has to be able to influence diners’ negative emotions first.

Second, if other customers in teppanyaki restaurant are loud and rude, diners are likely to feel angry and annoyed. Interestingly, this factor does not have the hypothesized effect on diners' positive emotions. This result is consistent with Chen et al.’s (2015) study of luxury restaurant consumption behavior. One possible explanation for the inability of other customers to affect positive emotions is that diners do not hold restaurants responsible for the good behavior of other customers; therefore, they do not feel excited about a restaurant simply because its customers are elegant and well mannered. However, if other customers in an upscale restaurant behave rudely, diners will be displeased because of their expectations regarding the clientele of such restaurants. Rude behavior and manners may also be easier to recognize in upscale restaurants than good manners and elegance. As demonstrated by Zainol, Lockwood, and Kutsch (2010), diners differ in their levels of tolerance for positive and negative encounters in restaurants. 
Third, contrary to previous research results on atmospherics (e.g., Jang \& Namkung, 2009; Chen et al., 2015), this study does not support the contention that atmospherics (e.g., lighting, décor, and design) affect diners’ positive emotions. However, the results support the hypothesis that atmospherics can affect diner negative emotions. One of the key elements for luxury restaurants is the need for conspicuous and superior atmospherics. The restaurants studied in the current study were located in four- and five-star hotels; therefore, the diners in these upscale restaurants should become upset if the atmospherics were inferior. However, the diners studied here did not become excited or pleased if the teppanyaki restaurant's atmospherics were superior perhaps because diners do not consider superior atmospherics as an important part of a teppanyaki restaurant.

Fourth, as expected, excellent service and superior food contribute to diners’ positive emotions toward a restaurant. Furthermore, poor service and tasteless food add to diners' negative emotions (Jang \& Namkung, 2009). Furthermore, as revealed by this research's mediating analysis, food quality is the only variable that can affect diners' loyalty directly and through affecting their emotions' first. In other words, it can be said that even in upscale teppanyaki restaurants where multiple methods are used to gratify diners' senses (i.e., nutrition value, freshness, tastiness, and visual attractiveness) is still restaurants’ core product (Kwun \& Oh, 2006).

Fifth, although teppanyaki chefs take orders from diners, prepare food in front of diners, and serve dishes to diners, service staff in teppanyaki restaurant must be knowledgeable regarding the restaurant and its menu as well as helpful and reliable because they affect diners' emotions. On the other hand, because teppanyaki restaurant chefs share some of the responsibilities that belong to service staff in other types of restaurant, the results obtained through mediating analysis reveal service staff 
in teppanyaki restaurants has no direct impact on diners' loyalty. Although service quality has been examined previously, the results obtained through mediating analysis provide additional insight into the role of service staff in teppanyaki restaurant.

\subsection{Managerial implications}

This study has several managerial implications for practitioners. The findings of this study can help teppanyaki restaurants and other restaurants in which chefs must directly serve diners to increase customer loyalty by assessing their environment and offerings. First, chefs are the most important investment for these restaurants. When chefs must serve customers directly, their responsibility is not limited to preparing delicious and healthy dishes. Because chefs work in front of diners, they may need to introduce and recommend different dishes to customers, such as explaining the uniqueness of each dish and describing to diners how ingredients are sourced and how they taste. In addition to being knowledgeable about the food, teppanyaki chefs must be proficient in interpersonal and communication skills to engage in conversations with customers, such as making appropriate remarks and being good listeners.

In addition to food knowledge and interpersonal skills, a good chef must be innovative and must have a good aesthetic sense because they display each dish in front of diners without assistance from other staff. Using standardized procedures to display certain dishes may decrease the pressure on chefs. Nevertheless, restaurants should encourage chefs to participate in different cultural activities, such as attending

music and art events. In the long term, such activities may help chefs to become more creative and aesthetically oriented when serving customers.

Other than top-quality chefs, food quality and service quality are two other factors worthy of investment. Chefs can be skillful, but diners will not be able to fully 
enjoy their meals unless the food is delicious and healthy. This statement is particularly relevant for teppanyaki restaurants because a meal's raw ingredients are often presented to diners before the chef prepares each dish. Teppanyaki restaurant management must invest in quality ingredients that are fresh and aesthetically pleasing. Although teppanyaki restaurant chefs share some of the responsibilities that belong to service staff in other types of restaurant, teppanyaki restaurant managers still must carefully train and retain their service staff. Service staff can not only influence the overall emotions of diners but also decrease the burden of chefs.

For managers of teppanyaki restaurants that have limited resources, satisfactory standards for atmospherics and customer behavior must be maintained (Zainol et al., 2010). However, management need not overspend when attempting to improve a restaurant's physical environment and need not establish high standards for customers, such as a dress code, as these factors do not contribute to diners' positive emotions. To prevent diners from affecting one another negatively, managers must consider seating arrangements. In teppanyaki restaurants that accept reservations, service staff can attempt to obtain more information regarding the purpose of a customer's visit (e.g., business or celebration of a special occasion) and the composition of his or her party (e.g., the number of young children and infants) prior to the visit. To ensure an acceptable level of atmospherics, managers can investigate the environments of nearby restaurants with similar clientele and pricing before designing the interior environment, lighting, and temperature of their own establishment.

\section{Limitations, Future Studies, and Conclusion}

Teppanyaki restaurants offer unique dining experience and are popular in some countries, such as Japan, Taiwan, France, and the US, but they have received little 
attention from scholars who study restaurant consumption. To the hospitality literature and practice, “chef's image” was incorporated into an extended M-R model to conceptualize diner loyalty to teppanyaki restaurants. In terms of the factors contributing to diners' positive emotions, food quality, atmospherics, interaction with other customers, chef image, and service quality have significant effects. However, only food quality, chef image, and service quality can significantly affect diners' positive emotions. As for the effects of positive emotions and negative emotions, the findings showed both emotions can affect diners' loyalty; furthermore, diners’ positive emotions and negative emotions can mediate restaurant-specific stimuli's influences on diners' loyalty. The managerial implications of this study are discussed.

Despite its contributions, this study has several limitations. First, this study focuses on teppanyaki restaurants located in four- and five-star hotels. However, some teppanyaki restaurants are not located in hotels but are located on important shopping avenues. Future research may seek to examine restaurants that are not located in hotels to ensure that perceptions of the hotel do not affect diners' perceptions of such restaurants. Second, this research did not consider the influence of companions and party size. According to Chang and Horng (2010), when consumers are not shopping alone, scholars need to consider this influence. Similarly, the influence of companions on diners should be evaluated when diners dine with friends or family members. Future research can investigate how companions may affect diners' emotions related to restaurant consumption. Moreover, it might be beneficial to the hospitality literature if researchers can explore how diners’ emotions can be affected by their party size. Finally, perceived price fairness can have a significant impact on the diners' satisfaction and loyalty (Bei \& Chiao, 2001; Xia, Monroe, \& Cox, 2004). The present study included teppanyaki restaurants in four- and five-star hotels to manage 
this factor's effect. Future studies might want to explore perceived price fairness's influence on diners' emotions and loyalty. 


\section{References}

1. Ali, F., Rezaei, S., Hussain, K., \& Ragavan, N.A. (2014). International business travellers' experience with luxury hotel restaurants: the impact of foodservice experience and customer satisfaction on dining frequency and expenditure. International Journal of Hospitality and Event Management, 1(2), 164-186.

2. Anderson, J.C., \& Gerbing, D.W. (1988). Structural equation modelling in practice: A review and recommended two-step approach. Psychological Bulletin, 103(3), 411-423.

3. Bagozzi, R. (1983). A holistic methodology for modelling consumer response to innovation. Operations Research, 31, 128-176.

4. Bagozzi, R., \& Yi, Y. (1988). On the evaluation of structural equation model. Journal of the Academy of Marketing Science, 16(1), 74-94.

5. Baker, J., \& Cameron, M. (1996). The effects of the service environment on affect and consumer perception of waiting time: An integrative review and research propositions. Journal of the Academy of Marketing Science, 24(4), 338349.

6. Batra, A. (2008). Foreign tourists' motivation and information source(s) influencing their preference for eating out at ethnic restaurants in Bangkok. International Journal of Hospitality and Tourism Administration, 9(1), 1-17.

7. Bei, L.T., \& Chiao, Y. C. (2001). An integrated model for the effects of perceived product, perceived service quality, and perceived price fairness on consumer satisfaction and loyalty. Journal of Consumer Satisfaction, Dissatisfaction and Complaining Behavior, 14, 125-40.

8. Berthon, P., Pitt, L., Parent, M., \& Berthon, J-P. (2009). Aesthetics and ephemerality: observing and preserving the luxury brand. California Management Review, 52(1), 45-66.

9. Brocato, E.D., Voorhees, C.M., \& Baker, J. (2012). Understanding the influence of cues from other customers in the service experience: A scale development and validation. Journal of Retailing, 88(3), 384-398.

10. Byrne, A., \& Whitehead, M. (2003). The naked truth of celebrity endorsement. British Food Journal, 105(4/5), 288-295.

11. Chang, R.C.Y., Kivela, J., \& Mak, A.H.N. (2010). Food preferences of Chinese tourists. Annals of Tourism Research, 37(4), 989-1011.

12. Chang, T-Y., \& Horng, S-C. (2010). Conceptualizing and measuring experience quality: the customer’s perspective. Service Industries Journal, 30(4), 24012419.

13. Chen, A., Peng, N., \& Hung, K-p. (2015). The effects of luxury restaurant 
environments on diners' emotions and loyalty: Incorporating diner expectations into an extended Mehrabian-Russell model. International Journal of Contemporary Hospitality Management, 27(2), 236-260.

14. Chin, W.W., Peterson, R.A., \& Brown, S.P. (2008). Structural equation modeling in marketing: some practical reminders. Journal of Marketing Theory \& Practice, 16(4), 287-289.

15. Choo, H., \& Petrick, J.F. (2014). Social interactions and intentions to revisit for agritouism service encounters. Tourism Management, 40, 372-381.

16. Commerce Industrial Service Portal. (2016). Inquiry services. Retrieved April 06, 2016 from Tripadvisor website: http://gcis.nat.gov.tw/mainNew/.

17. Fang, C-Y., Peng, P-Y(J)., \& Pan W-T(W). (2013). Does using an a`la carte or combo set menu affect the performance of a teppanyaki-style restaurant?. International Journal of Contemporary Hospitality Management, 25(4), 491509.

18. Fornell, C., \& Larcker, D. (1981). Evaluating structural equation models with unobservable variables and measurement errors. Journal of Marketing Research, 18(1), 39-50.

19. Halonen-Knight, E., \& Hurmerinta, L. (2010). Who endorses whom? Meanings transfer in celebrity endorsement. Journal of Product \& Brand Management, 19(6), 452-460.

20. Han, H., \& Back, K-J. (2008). Relationships among image congruence, consumption emotions, and customer loyalty in the lodging industry. Journal of Hospitality \& Tourism Research, 32(4), 467-490.

21. Han, H., \& Ryu, K. (2009). The roles of the physical environment, price perception, and customer satisfaction in determining customer loyalty in the restaurant industry. Journal of Hospitality \& Tourism Research, 33(4), 487-510.

22. Harrington, R.J., Ottenbacher, M.C., \& Kendall, K.W. (2011). Fine-Dining Restaurant Selection: Direct and Moderating Effects of Customer Attributes. Journal of Foodservice Business Research, 14(3), 272-289.

23. Huang, S(S)., \& Hsu, C.H.C. (2009). Effects of travel motivation, past experience, perceived constraint, and attitude on revisit intention. Journal of Travel Research, 48(1), 29-44.

24. Jang, S(S)., \& Namkung, Y. (2009). Perceived quality, emotions, and behavioural intentions: Application of an extended Mehrabian-Russell model to restaurants. Journal of Business Research, 62(4), 451-460.

25. Johnson, C., Surlemont, B., Nicod, P., \& Revaz, R. (2005). A concise typology of Michelin restaurants in Europe. Cornell Hotel and Restaurant Administration Quarterly, 46(2), 170-187. 
26. Kaltcheva, V.D., \& Weitz, B.A. (2006). When should a retailer create an exciting store environment. Journal of Marketing, 70(1), 107-118.

27. King, S.C., \& Meiselman, H.L. (2010). Development of a method to measure consumer emotions associated with foods. Food Quality and Preference, 21(2), 168-177.

28. King, S.C., Meiselman, H.L., \& Carr, B.T. (2010). Measuring emotions associated with foods in consumer testing. Food Quality and Preference, 21(8), 1114-1116.

29. Kline, R.B. (2005). Principles and Practices of Structural Equation Modeling $\left(2^{\text {nd }}\right)$. New York, NY: The Guilford Press.

30. Ko, W.H., Hsiao, C.Y. (2008). To evaluate the professional competency of chefapplying in analysis hierarchy process. Journal of Hospitality and Home Economics, 5, 69-91.

31. Koo, D-M., \& Ju, S-H. (2010). The interactional effects of atmospherics and perceptual curiosity on emotions and online shopping intention. Computers in Human Behavior, 26(3), 377-388.

32. Kotler, P. (1973). Atmospherics as a marketing tool. Journal of Retailing, 49(4), 48-64.

33. Kuroshima, S. (2010). Another look at the service encounter: Progressivity, intersubjectivity, and trust in a Japanese sushi restaurant. Journal of Pragmatics, 42, 856-869.

34. Kwun, D.J-W., \& Oh, H. (2006). Past experience and self-image in fine dining intentions. Journal of Foodservice Business Research, 9(4), 3-23.

35. Law, R., To, T., \& Goh, G. (2008). How do mainland Chinese travelers choose restaurants in Hong Kong?: An exploratory study of individual visit scheme travelers and packaged travelers. International Journal of Hospitality Management, 27(3), 346-354.

36. Lee, J.H., \& Hwang, J. (2011). Luxury marketing: The influences of psychological and demographic characteristics on attitudes toward luxury restaurants. International Journal of Hospitality Management, 30(3), 658-669.

37. Lehto, X., O’Leary, J., \& Morrison, A. (2004). The effect of prior experience on vacation behaviour. Annals of Tourism Research, 31, 801-818.

38. Lin, C-N., \& Lin, H-S. (2006). The study of chef image and consumer behavior of teppanyaki restaurant in Taipei. Hwa Kang Journal of Agriculture, 7, 13-26.

39. Liu, Y., \& Jang, S(S). (2009). The effects of dining atmospherics: An extended Mehrabian-Russell model. International Journal of Hospitality Management, 28(4), 494-503. 
40. MacKinnon, D.P., Lockwood, C.M., \& Williams, J. (2004). Confidence limits for the indirect effect: Distribution of the product and resampling methods. Multivariate Behavioral Research, 39, 99-128.

41. Mehrabian, A., \& Russell, J.A. (1974). An Approach to Environmental Psychology. Cambridge, MA: MIT Press.

42. Min, K-H., \& Lee, T.J. (2014). Customer satisfaction with Korean restaurants in Australia and their role as ambassadors for tourism marketing. Journal of Travel and Tourism Marketing, 31(4), 493-506.

43. Mohsin, A., \& Lockyer, T. (2010). Customer perceptions of service quality in luxury hotels in New Delhi, India: An exploratory study. International Journal of Contemporary Hospitality Management, 22(2), 160-173.

44. Nam, J-H., \& Lee, T.J. (2011). Foreign travelers' satisfaction with traditional Korean restaurants. International Journal of Hospitality Management, 30, 982989.

45. Oliver, R.L. (1999). Whence consumer loyalty? Journal of Marketing, 63, 33-44.

46. Ong, F.S., \& Khong, K.W. (2011). The effects of mall atmospherics and convenience on flow: A study of shoppers in Malaysia. The Business \& Management Review, 1(2), 78-87.

47. Parasuraman, A., Zeithaml, V.A., \& Berry, L.L. (1988). Servqual: A multipleitem scale for measuring consumer perceptions of service quality. Journal of Retailing, 64(1), 12-40.

48. Peng, N., \& Chen, A.H. (2015). Diners' loyalty toward luxury restaurants: the moderating effect of product knowledge. Marketing Intelligence \& Planning, 33(2), 179-196.

49. Pratten, J.D. (2003a).The training and retention of chefs. International Journal of Contemporary Hospitality Management, 15(4), 237-242.

50. Pratten, J.D. (2003b). What makes a great chef? British Food Journal, 105(7), 454-459.

51. Preacher, K. J., \& Hayes, A. F. (2008). Asymptotic and resampling strategies for assessing and comparing indirect effects in multiple mediator models. Behavior Research Methods, 40, 879-891.

52. Ryu, K., Lee, H-R., \& Kim, G. (2012). The influence of the quality of the physical environment, food, and service on restaurant image, customer perceived value, customer satisfaction, and behavioral intentions. International Journal of Contemporary Hospitality Management, 24(2), 200-223.

53. Tai, S.H.C., \& Fung, A.M.C. (1997). Application of an environmental psychology model to in-store buying behaviour. The International Review of Retail, Distribution and Consumer Research, 7(4), 311-337. 
54. Taiwan Stay. (2015), Star Hotels. Retrieved April, 24 $4^{\text {th }}, 2016$ from Taiwan Stay website: http://taiwanstay.net.tw/.

55. Tripadvisor. (2016). Restaurants in Taiwan. Retrieved April 06, 2016 from Tripadvisor website: https://www.tripadvisor.com/Restaurants-g293910Taiwan.html.

56. Westbrook, R.A. (1987). Product/consumption-based affective responses and postpurchase processes. Journal of Service Marketing, 24(3), 258-270.

57. Wu, C.H-J., \& Liang, R-D. (2009). Effect of experiential value on customer satisfaction with service encounters in luxury-hotel restaurants. International Journal of Hospitality Management, 28, 586-593.

58. Xia, L., Monroe, K.B., \& Cox, J.L. (2004). The price is unfair! A conceptual framework of price fairness perceptions. Journal of Marketing, 68(4), 1-15.

59. Yuksel, A. (2007). Tourist shopping habitat: Effects on emotions, shopping value and behaviours. Tourism Management, 28(1), 58-69.

60. Zainol, N.A., Lockwood, A., \& Kutsch, E. (2010). Relating the zone of tolerance to service failure in the hospitality industry. Journal of Travel and Tourism Marketing, 27(3), 324-333.

61. Zopiatis, A. (2010). Is it art or science? Chef's competencies for success. International Journal of Hospitality Management, 29, 459-467. 
Table 1- Characteristics of the participants $(\mathrm{N}=308)$

\begin{tabular}{|c|c|c|}
\hline Variables & Traits & $\%$ \\
\hline \multirow{2}{*}{ Gender } & Male & 42.9 \\
\hline & Female & 57.1 \\
\hline \multirow{4}{*}{ Marital status } & Married & 51.4 \\
\hline & Unmarried & 48.7 \\
\hline & $18-30$ & 22.7 \\
\hline & $31-40$ & 29.2 \\
\hline \multirow[t]{4}{*}{ Age } & $41-50$ & 25.9 \\
\hline & $51-60$ & 13.6 \\
\hline & 61 and above & 8.4 \\
\hline & Lower than high school degree & 2.9 \\
\hline \multirow{5}{*}{ Education } & High school degree & 8.1 \\
\hline & University or college degree & 52.9 \\
\hline & Postgraduate degree or above & 36.1 \\
\hline & Below $\$ 708$ & 3.9 \\
\hline & $\$ 709-\$ 1,030$ & 10.0 \\
\hline \multirow{5}{*}{$\begin{array}{l}\text { Income per } \\
\text { month (US\$) }\end{array}$} & $\$ 1,031-\$ 1,352$ & 15.3 \\
\hline & $\$ 1,353-\$ 1,674$ & 18.8 \\
\hline & $\$ 1,675-\$ 1,996$ & 19.5 \\
\hline & $\$ 1,997-\$ 2,318$ & 14.3 \\
\hline & Above $\$ 2,319$ & 18.2 \\
\hline \multirow{7}{*}{$\begin{array}{l}\text { Teppanyaki } \\
\text { restaurant } \\
\text { dining } \\
\text { frequency }\end{array}$} & More than once per week & 2.0 \\
\hline & Once per week & 6.8 \\
\hline & Once every two weeks & 18.8 \\
\hline & Once per month & 39.2 \\
\hline & Once every two months & 24.7 \\
\hline & Once every three months & 4.9 \\
\hline & Once every three to six months & 3.6 \\
\hline \multirow{3}{*}{$\begin{array}{l}\text { Area of } \\
\text { residence }\end{array}$} & Taipei City & 51.3 \\
\hline & Taichung & 26.0 \\
\hline & Kaohsiung & 22.7 \\
\hline
\end{tabular}


Table 2 Results from Exploratory Factor Analysis ( $N=148)$

\begin{tabular}{|c|c|c|c|c|c|c|}
\hline Variable & Measurement items & Mean & SD & $\begin{array}{l}\text { Factor } \\
\text { loading }\end{array}$ & $\alpha$ & Adopted from \\
\hline \multicolumn{7}{|c|}{ Stimuli (S) $\left(\mathrm{KMO}=0.90\right.$; Barlet's $\left.\chi^{2}=1972.39\right)$} \\
\hline \multirow[t]{4}{*}{ Food quality } & 1: Food presentation is visually attractive. & 5.82 & 0.88 & 0.82 & 0.93 & \multirow{4}{*}{$\begin{array}{l}\text { Jang and Namkung, } \\
\text { (2009) }\end{array}$} \\
\hline & 2: The restaurant serves tasty food. & 5.38 & 1.12 & 0.94 & & \\
\hline & 3: The restaurant offers fresh food. & 5.55 & 1.05 & 0.93 & & \\
\hline & 4: The restaurant offers healthy options & 5.34 & 1.13 & 0.93 & & \\
\hline \multirow[t]{3}{*}{ Service quality } & $\begin{array}{l}\text { 1: The staff provides a thorough and satisfactory } \\
\text { service. }\end{array}$ & 5.60 & 0.97 & 0.82 & 0.88 & \multirow[t]{3}{*}{ Chen et al. (2015) } \\
\hline & 2: The staff is reliable. & 5.77 & 0.87 & 0.80 & & \\
\hline & 3: The staff is professional. & 5.66 & 0.99 & 0.80 & & \\
\hline \multirow[t]{3}{*}{ Atmospherics } & 1: Restaurant's decoration is impressive. & 2.54 & 1.23 & 0.84 & 0.74 & \multirow{3}{*}{$\begin{array}{l}\text { Liu and Jang (2009); } \\
\text { Jang and Namkung } \\
\text { (2009) }\end{array}$} \\
\hline & 2: Restaurant's interior design is appealing. & 2.47 & 1.11 & 0.84 & & \\
\hline & 3: Restaurant's atmosphere is luxurious. & 1.97 & 0.86 & 0.76 & & \\
\hline \multirow{3}{*}{$\begin{array}{l}\text { Interaction with other } \\
\text { customers }\end{array}$} & 1: Other customers are elegant. & 5.55 & 1.14 & 0.80 & 0.86 & \multirow[t]{3}{*}{ Chen et al. (2015) } \\
\hline & 2: Other customers have good manners. & 5.27 & 1.12 & 0.88 & & \\
\hline & $\begin{array}{l}\text { 3: It is pleasant to interact with other customers. } \\
\text { The chef... }\end{array}$ & 5.40 & 1.14 & 0.82 & & \\
\hline \multirow[t]{2}{*}{ Chef's image } & $\begin{array}{l}\text { 1: explains his / her food preparation method and } \\
\text { the uniqueness of each dish. }\end{array}$ & 5.11 & 1.05 & 0.80 & & \multirow[t]{2}{*}{ Lin and Lin (2006) } \\
\hline & 2: is innovative. & 4.93 & 1.08 & 0.88 & & \\
\hline
\end{tabular}



3: has good aesthetics sense.
$\begin{array}{lll}4.85 & 1.08 & 0.87\end{array}$
4: has good interpersonal skills.
$4.84 \quad 1.19 \quad 0.76$

Organisms (O) $\left(\mathrm{KMO}=0.82\right.$; Barlet's $\left.\chi^{2}=643.94\right)$

Positive emotions $\quad$ I feel... not at all (1)- Strongly (7)

1: Joy (joyful, pleased, romantic, welcoming).

2: Excitement (excited, thrilled, enthusiastic).

$\begin{array}{lll}5.21 & 1.11 & 0.88\end{array}$

$\begin{array}{lll}5.31 & 1.08 & 0.88\end{array}$

0.89

Liu and Jang (2009);

3: Peacefulness (comfortable, relaxed, at rest).

$\begin{array}{lll}5.27 & 1.04 & 0.84\end{array}$

(2009)

I feel... not at all (1)- Strongly (7)

Negative emotions

1: Anger (angry, irritated)

$2.78 \quad 1.14 \quad 0.93$

$2.75 \quad 1.11 \quad 0.90$

0.90

Liu and Jang (2009);

2: Distress (frustrated, disappointed, upset)

$\begin{array}{lll}2.38 & 0.91 & 0.77\end{array}$

(2009)

$\underline{\text { Response (R) }}\left(\mathrm{KMO}=0.77\right.$; Barlet's $\left.\chi^{2}=368.45\right)$

Loyalty

1: I would like to come back to this restaurant in

$5.22 \quad 0.93$

0.95

0.94

Liu and Jang (2009); the future.

$\begin{array}{lll}5.18 & 0.99 & 0.94\end{array}$

2: I plan to revisit this restaurant in the future.

$\begin{array}{lll}5.41 & 0.92 & 0.94\end{array}$

friends or others.

1. “[The chef] makes delicious dishes” from "Chef’s Image” was eliminated due to cross loading. 
Table $3 \underline{\text { Results from Confirmatory Factor Analysis (N=160) }}$

\begin{tabular}{|c|c|c|c|c|}
\hline \multirow[t]{2}{*}{ Variable } & \multirow[t]{2}{*}{ Measurement items } & \multicolumn{3}{|c|}{ CFA } \\
\hline & & SFL & AVE & $\mathrm{CR}$ \\
\hline \multicolumn{5}{|l|}{ Stimuli (S) } \\
\hline \multirow[t]{4}{*}{ Food quality } & 1: Food presentation is visually attractive. & 0.80 & 0.77 & 0.93 \\
\hline & 2: The restaurant serves tasty food. & 0.91 & & \\
\hline & 3: The restaurant offers fresh food. & 0.89 & & \\
\hline & 4: The restaurant offers healthy options & 0.91 & & \\
\hline \multirow[t]{3}{*}{ Service quality } & $\begin{array}{l}\text { 1: The staff provides a thorough and satisfactory } \\
\text { service. }\end{array}$ & 0.87 & 0.67 & 0.86 \\
\hline & 2: The staff is reliable. & 0.84 & & \\
\hline & 3: The staff is professional. & 0.86 & & \\
\hline \multirow[t]{3}{*}{ Atmospherics } & 1: Restaurant's decoration is impressive. & 0.76 & 0.58 & 0.80 \\
\hline & 2: Restaurant's interior design is appealing. & 0.81 & & \\
\hline & 3: Restaurant's atmosphere is luxurious. & 0.71 & & \\
\hline \multirow{3}{*}{$\begin{array}{l}\text { Interaction with other } \\
\text { customers }\end{array}$} & 1: Other customers are elegant. & 0.75 & 0.71 & 0.88 \\
\hline & 2: Other customers have good manners. & 0.92 & & \\
\hline & $\begin{array}{l}\text { 3: It is pleasant to interact with other customers. } \\
\text { The chef... }\end{array}$ & 0.85 & & \\
\hline \multirow[t]{2}{*}{ Chef's image } & $\begin{array}{l}\text { 1: explains his / her food preparation method and the } \\
\text { uniqueness of each dish. }\end{array}$ & 0.82 & 0.75 & 0.92 \\
\hline & 2: is innovative. & 0.95 & & \\
\hline
\end{tabular}


3: has good aesthetics sense. $\quad 0.94$

4: has good interpersonal skills. $\quad 0.73$

Organisms (O)

Positive emotions $\quad$ I feel... not at all (1)- Strongly (7)

1: Joy (joyful, pleased, romantic, welcoming). $\quad \begin{array}{lll}0.78 & 0.79 & 0.92\end{array}$

2: Excitement (excited, thrilled, enthusiastic). 0.93

3: Peacefulness (comfortable, relaxed, at rest). $\quad 0.94$

Negative emotions $\quad$ I feel... not at all (1)- Strongly (7)

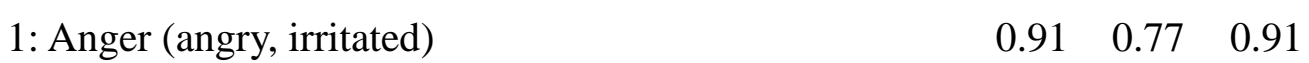

2: Distress (frustrated, disappointed, upset) $\quad 0.95$

3: Disgust (disgusted, displeased, bad) 0.77

$\underline{\text { Response (R) }}$

Loyalty 1: I would like to come back to this restaurant in the

$\begin{array}{lll}0.94 & 0.83 & 0.94\end{array}$ future.

2: I plan to revisit this restaurant in the future. 0.94

3: I would recommend this restaurant to my friends or $\quad 0.85$ others. 


\section{Table 4 Correlation between Constructs following CFA}

\begin{tabular}{|c|c|c|c|c|c|c|c|c|}
\hline & FQ & SQ & A & IOC & CI & $\mathrm{PE}$ & $\mathrm{NE}$ & $\mathrm{L}$ \\
\hline 1. Food quality (FQ) & .88 & & & & & & & \\
\hline 2. Service quality (SQ) & .53 & .84 & & & & & & \\
\hline 3. Atmospherics (A) & -.54 & -.47 & .74 & & & & & \\
\hline 4. Interaction with other customers (IOC) & .45 & .36 & -.54 & .84 & & & & \\
\hline 5. Chef's image (CI) & .68 & .48 & -.51 & .41 & .87 & & & \\
\hline 6. Positive emotions (PE) & .53 & .51 & -.39 & .27 & .52 & .88 & & \\
\hline 7. Negative emotions (NE) & -.58 & -.61 & .37 & -.40 & -.58 & -.62 & .88 & \\
\hline 8. Loyalty (L) & .52 & .40 & -.53 & .30 & .57 & .58 & -.53 & .91 \\
\hline
\end{tabular}

- $p<0.01,{ }^{\text {a }}$ Bold numbers on the diagonal parentheses are square root of each construct's AVE value 
Table 5 Hypotheses Tests $(\mathrm{N}=308)$

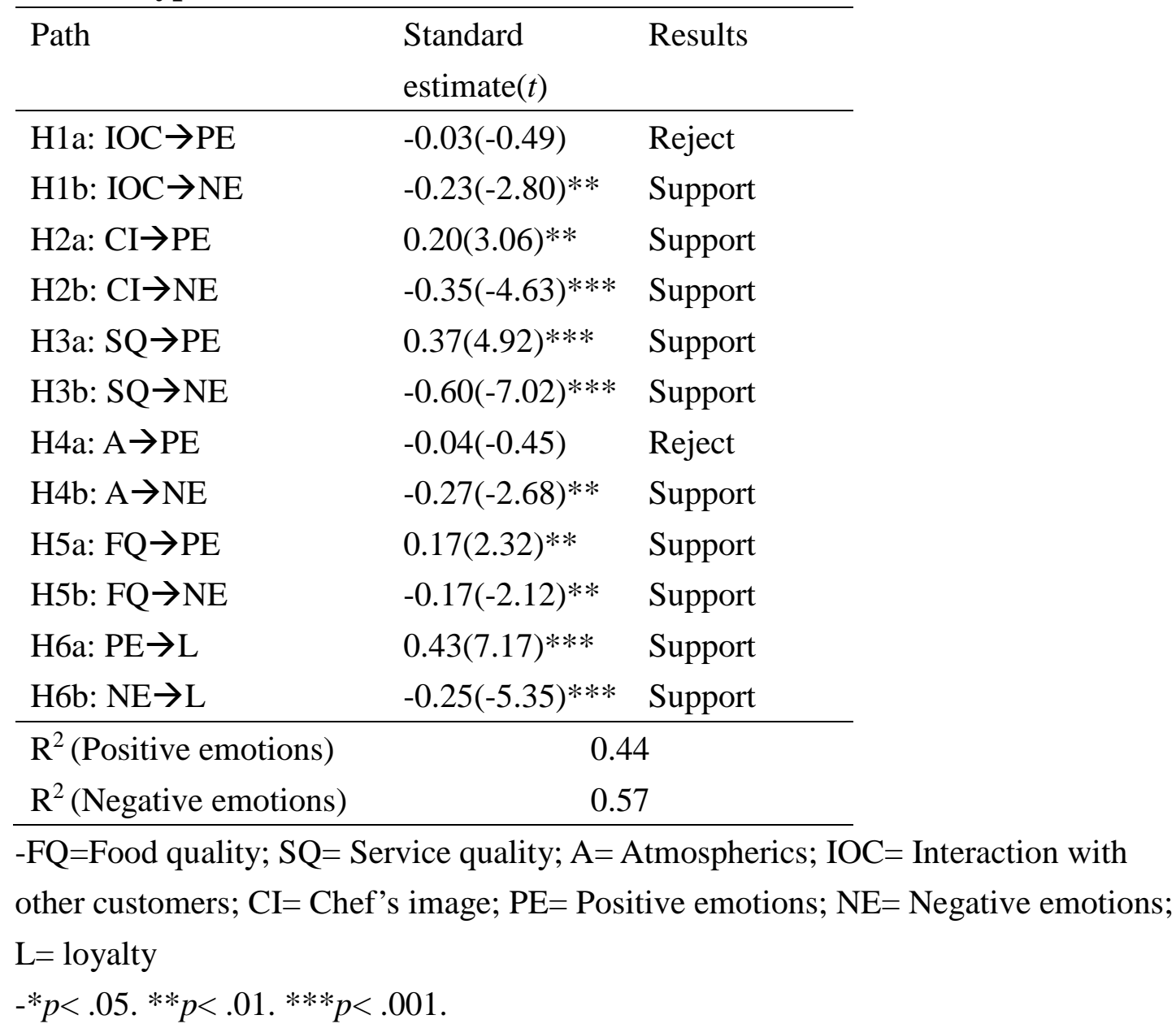




\section{Table 6 Emotion's Mediating Effect (H7a and H7b)}

\begin{tabular}{|c|c|c|c|c|c|c|c|}
\hline $\begin{array}{l}\text { Independent } \\
\text { variable (IV) }\end{array}$ & $\begin{array}{l}\text { Mediating } \\
\text { variable (M) }\end{array}$ & $\begin{array}{l}\text { Dependent } \\
\text { variable (DV) }\end{array}$ & $\begin{array}{l}\text { Total } \\
\text { effect (c) }\end{array}$ & $\begin{array}{l}\text { Effect of IV } \\
\text { on M (a) }\end{array}$ & $\begin{array}{l}\text { Effect of M } \\
\text { on DV (b) }\end{array}$ & $\begin{array}{l}\text { Direct effect } \\
\text { (c') }\end{array}$ & Result \\
\hline Chef's image & \multirow{3}{*}{$\begin{array}{l}\text { Positive } \\
\text { emotions }\end{array}$} & \multirow{3}{*}{ Loyalty } & $0.46 * * *$ & $0.50 * * *$ & $0.34 * * *$ & $0.29 * * *$ & Partially mediate \\
\hline Service quality & & & $0.42 * * *$ & $0.63 * * *$ & $0.43^{* * *}$ & 0.14 & Fully mediate \\
\hline Food quality & & & $0.52 * * *$ & $0.62 * * *$ & $0.36^{* * *}$ & $0.29 * * *$ & Partially mediate \\
\hline $\begin{array}{l}\text { Interaction with } \\
\text { other customers }\end{array}$ & \multirow{5}{*}{$\begin{array}{l}\text { Negative } \\
\text { emotions }\end{array}$} & \multirow{5}{*}{ Loyalty } & $0.25 * * *$ & $-0.37 * * *$ & $-0.45 * * *$ & 0.09 & Fully mediate \\
\hline Chef's image & & & $0.47 * * *$ & $-0.52 * * *$ & $-0.28 * * *$ & $0.32 * * *$ & Partially mediate \\
\hline Service quality & & & $0.42 * * *$ & $-0.69 * * *$ & $-0.42 * * *$ & 0.13 & Fully mediate \\
\hline Atmospherics & & & $0.56 * * *$ & $-0.43 * * *$ & $-0.36 * * *$ & $0.41 * * *$ & Partially mediate \\
\hline Food quality & & & $0.52 * * *$ & $-0.63 * * *$ & $-0.32 * * *$ & $0.31^{* * *}$ & Partially mediate \\
\hline
\end{tabular}


Figure 1. Research Framework $(\mathrm{N}=308)$

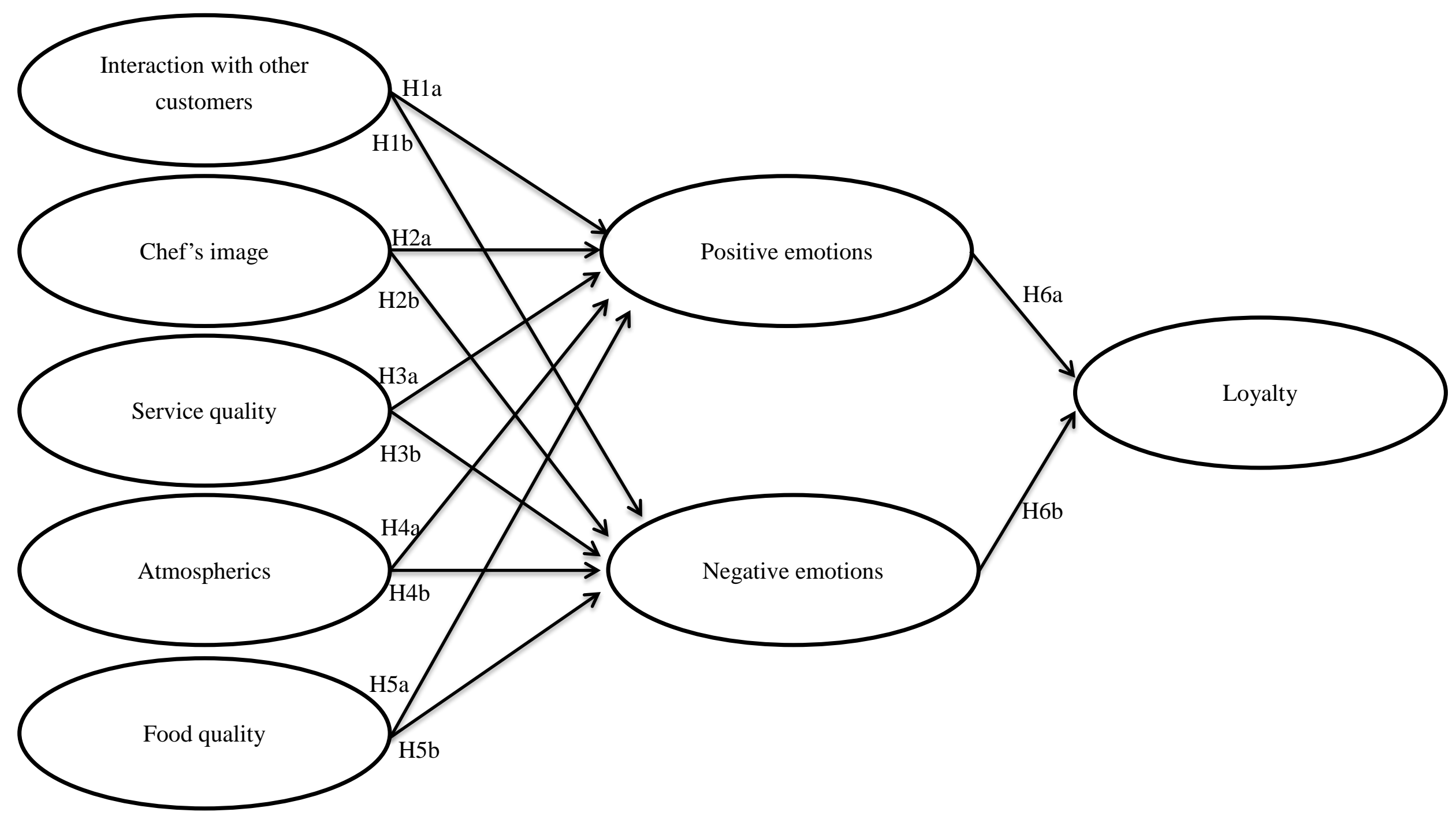


Figure 2. Results from Analysis $(\mathrm{N}=308)$

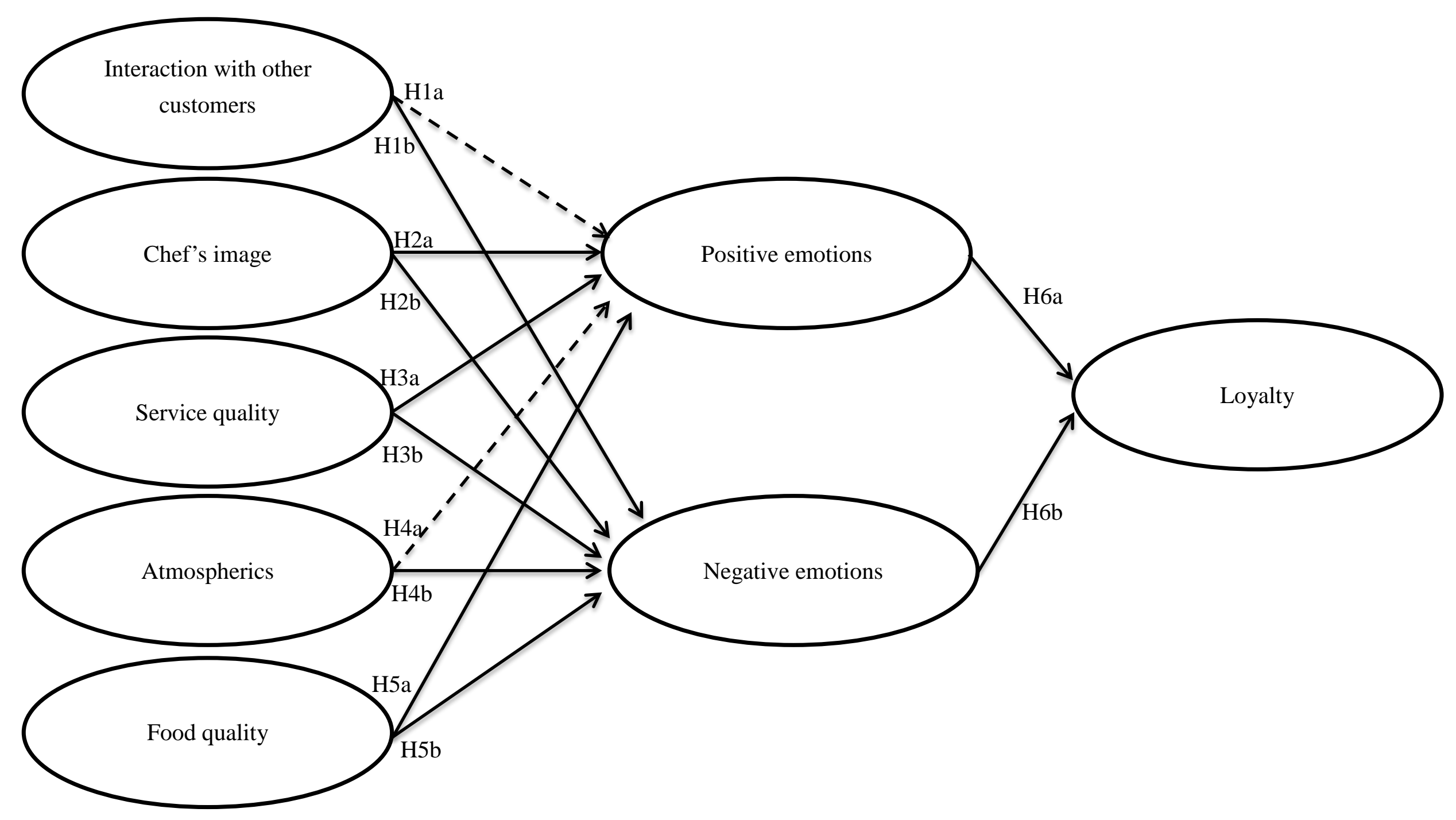


Appendix A- Descriptive statistics for price range of the observed teppanyaki restaurants

\begin{tabular}{ccc}
\hline \hline Restaurant & $\begin{array}{c}\text { Dinner price per person } \\
\text { (average) }\end{array}$ & $\begin{array}{c}\text { Dinner price per person } \\
\text { (range) }\end{array}$ \\
\hline A & $\$ 68$ & $\$ 57-\$ 79$ \\
B & $\$ 59$ & $\$ 47-\$ 69$ \\
C & $\$ 134$ & $\$ 52-\$ 206$ \\
D & $\$ 41$ & $\$ 38-\$ 44$ \\
E & $\$ 58$ & $\$ 53-\$ 63$ \\
F & $\$ 55$ & $\$ 47-\$ 63$ \\
G & $\$ 91$ & $\$ 91-\$ 111$ \\
H & $\$ 69$ & $\$ 43-\$ 94$ \\
I & $\$ 107$ & $\$ 47-\$ 168$ \\
J & $\$ 32$ & $\$ 25-\$ 38$ \\
K & $\$ 28$ & $\$ 25-\$ 32$ \\
L & $\$ 83$ & $\$ 58-108$ \\
\hline
\end{tabular}


